\title{
O ABSURDO DA INTERPRETAÇÃO ECONÔMICA DO "FATO GERADOR" Direito e sua autonomia - o paradoxo da interdisciplinariedade
}

\author{
THE ABSURD OF THE ECONOMIC INTERPRETATION OF THE "TAXABLE EVENT" \\ Law and its autonomy - the paradox of the interdisciplinity
}

\section{Paulo de Barros Carvalho ${ }^{1}$}

À memória de Alfredo Augusto Becker

\begin{abstract}
Resumo
O objetivo do presente texto é pôr em evidência, ainda que a breve trecho, a autonomia do Direito em relação a outras matérias que lhe são próximas, firmando premissas no caráter sintaticamente homogêneo que o Direito Positivo apresenta enquanto sistema, formado por unidades atômicas - as normas jurídicas - expressas verbalmente por meio de proposições prescritivas. Releve-se, outrossim, que o campo material do conteúdo normativo está no universo empírico que, apresentando-se infinito em seus caracteres, impõe cortes e mais recortes, que cumprem a função de simplificar a complexa realidade existencial, ao mesmo tempo em que circunscrevem o campo da análise. A disciplina revela-se pelo critério adotado no corte, pois está nele a localização do sistema e a conseqüente qualificação do fato construído em linguagem. De tal forma que não há fatos jurídicos puros ou fatos econômicos puros. O que existe são cortes de linguagem. Os fatos, assim como toda construção de linguagem, podem ser observados como jurídicos, econômicos, antropológicos, históricos, políticos, contábeis etc.; tudo dependendo do critério adotado pela incisão metodológica empreendida. A cada secção, uma disciplina; e a cada disciplina, um método de aproximação. Esta exigência cognoscitiva não exclui, por outro giro, que disciplinas diferentes conversem entre si. Sem disciplinas, é claro, não teremos as interdisciplinas, mas o próprio saber disciplinar, em função do princípio da intertextualidade, avança na direção de outros setores do conhecimento, buscando a indispensável complementariedade. O paradoxo é inevitável: o disciplinar leva ao interdisciplinar e este último faz retornar ao primeiro.
\end{abstract}

Palavras-chaves: Fato jurídico. Fato econômico. Interpretação. Interpretação econômica. Fato puro. Corte. Disciplina. Interdisciplinas.

\begin{abstract}
The purpose of this text is to put in evidence, even if briefly, the autonomy of the Law in regards to other subjects related to it, establishing premises in the syntactically homogeneous character presented at the Positive Law as a system, constituted by atomic units - the legal rules - expressed orally by means of prescriptive propositions. Note, further, that the material scope of the normative tenor is in the empiric universe that, endless with respect to its characters, imposes cuts and prunes, which simplify the complex existential reality, at the same time in which they limit the analysis sphere. The discipline is revealed by the criteria adopted at the cut, since there is the system localization and consequent qualification of the fact built into language. In
\end{abstract}

Professor Titular do Departamento de Direito Econômico-Financeiro da Faculdade de Direito da Universidade de São Paulo. Professor Titular da Pontifícia Universidade Católica de São Paulo. 
a manner that there are not legal material facts or economic material facts, but only cuts of language. The facts, as well as the construction of the language, may be seen as legal, economic, anthropologic, historic, politic, accounting, etc.; depending on the criteria adopted by the methodological incision used. In each cut, a discipline; and in each discipline, an approach method. Such knowledge requirement does not prevent, on the other hand, that different disciplines relate to each other. Without disciplines, it is obvious, there will be no interdisciplines, but the proper discipline knowledge, in function of the intertextuality principle, going in the direction of other knowledge sectors, seeking its utmost complement. The paradox cannot be avoided: teaching leads to interdiscipline and interdiscipline leads to teaching.

Keywords: Legal fact. Economic fact. Interpretation. Economic interpretation. Material fact. Cut. Discipline. Interdisciplines.

\section{Introdução}

O objetivo do presente texto é pôr em evidência, ainda que a breve trecho, a autonomia do Direito em relação a outras matérias que lhe são próximas, firmando premissas no caráter sintaticamente homogêneo que o Direito Positivo apresenta enquanto sistema empírico, formado por unidades atômicas - as normas jurídicas - expressas verbalmente por meio de proposições prescritivas. Descansa, portanto, em duas premissas: a) que o direito posto, como camada lingüística, se estrutura em forma de sistema autônomo; e b) que os elementos desse conjunto são normas jurídicas (aqui utilizadas no sentido estrito), expressas mediante proposições hipotético-implicacionais. A partir daí, coloca-se a tese segundo a qual um dos aspectos do referido sistema é, justamente, o de ser homogêneo, em termos sintáticos, constituinte de uma realidade propriamente sua.

Prescindível advertir que cada uma das palavras utilizadas nesta estrita comunicação serve de tema para amplos e intermináveis confrontos acadêmicos. As construções jurídico-filosóficas têm demonstrado, iterativamente, que os mais singelos vocábulos da terminologia que empregamos oferecem precioso material para discordâncias fundamentais, dentro mesmo de uma só corrente de pensamento. Entretanto, para tornar possível o isolamento temático da proposta, suspendo, momentaneamente, a atenção sobre os problemas que porventura possam ser suscitados, voltando-a para o exame tópico de certos pontos, a propósito dos quais aduzirei algumas considerações que me parecem oportunas.

\section{O conteúdo prescritivo da linguagem do Direito Positivo}

Dou por assente que o estudo do Direito Positivo, como estrato de linguagem, não-implica uma tomada de posição redutora do fenômeno jurídico, mas que supõe admitir 
que o conjunto de símbolos empregados para a comunicação entre os seres humanos, no contexto social, adquira uma das formas particulares de interação simbólica, compatível com a função reguladora do Direito, na alteridade substancial que lhe é imanente. E esse modo específico é o da linguagem prescritiva.

De fato, tanto o discurso informativo, próprio para as transmissões cognoscitivas; quanto o expressivo de situações subjetivas, como as emoções; e ainda aquele peculiar à formulação de perguntas, que reflete a perplexidade do sujeito, ao pé de realidades que desconhece; essas três funções da linguagem não se ajustam ao fim primordial do Direito, na sua missão disciplinadora de relações intersubjetivas. Para realizar tal finalidade ordenadora, o instrumento adequado é a linguagem prescritiva de situações, ou seja, "da linguagem cuja finalidade é alterar a circunstância, e cujo destinatário é o homem e sua conduta no universo social. Altera-se o mundo físico mediante o trabalho e a tecnologia, que o potencia em resultados. E altera-se o mundo social mediante a linguagem das normas, uma classe da qual é a linguagem das normas do Direito", como se extrai da lição vigorosa de Lourival Vilanova. ${ }^{2}$

Pois bem, esse caráter prescritivo, vectorial, penetra intensamente toda a textura do sistema do Direito posto que se verte sobre a facticidade social, qualificando pessoas, situações e coisas, exatamente para associar-lhes a regulação das condutas interhumanas.

3. Observações a respeito das unidades que compõem o sistema do Direito Positivo

Quando menciono o direito posto, na condição de sistema, é para encará-lo não como sistema lógico, dotado de consistência, isento de contradições, tal qual o modelo do sistema das ciências, mas como conjunto de proposições lingüísticas que se dirigem a certa e determinada região material - a região material das condutas interpessoais. $\mathrm{O}$ discurso de que falo, conquanto abrigue proposições contraditórias e lacunas, mesmo assim vem carregado de uma porção de racionalidade que julgo suficiente para outorgarlhe foros de sistema, não-lógico, mas empírico, precisamente pelo comprometimento que mantém com o tecido social, por ele ordenado de maneira prescritiva.

Ora, guardando a forma de sistema, as unidades que compõem o Direito Positivo são as normas jurídicas, juízos hipotético-condicionais, em que se enlaça ao antecedente, ou descritor, um conseqüente, ou prescritor, tudo por intermédio da cópula

2 VILANOVA, Lourival. As estruturas lógicas e o sistema do Direito Positivo. São Paulo: Revista dos Tribunais, 1977. p. 3-4. 
deôntica - o “dever-ser”, na sua configuração neutra, isto é, sem modalização. Essas entidades lógicas (os juízos hipotéticos) ganham expressão verbal no jeito de proposições - proposição hipótese e proposição tese - entreligadas pelo conectivo peculiar ao domínio do normativo-social, a que já me referi.

É bom lembrar que, nos fenômenos de incidência normativa, componentes de uma nova realidade jurídica, há duas normas que devem ajustar-se, respectivamente, a norma geral e abstrata e a norma individual e concreta. No plano da formulação normativa, tudo se inicia quando da construção de uma classe ou conjunto enumerando os indivíduos que a compõem, ou indicando as notas ou nota que o indivíduo precisa ter para pertencer à classe ou conjunto. A primeira, é a forma tabular; a segunda, forma-deconstrução. A modalidade em que, quase sempre, se manifesta a proposição normativa geral e abstrata não é a forma tabular, mas a forma-de-construção. Nela se estatuem as notas (conotação) que os sujeitos ou as ações devem ter para pertencerem ao conjunto. A relação de pertinencialidade é determinada conotacionalmente. Este o modo mais freqüente no Direito Positivo. Seria infindável formar classes pela enumeração dos indivíduos ou ações, já que o real é irrepetível e a experiência é infinita e inesgotável.

Cada enunciado que venha a ser formado, contendo os caracteres selecionados na composição típica da hipótese, subsumir-se-á naquele conjunto que, dessa maneira, poderá receber número infinito de ocorrências fácticas. É bom ter presente que a formação desses segmentos lingüísticos com sentido completo pressupõe um processo seletivo, com a eleição dos traços julgados mais relevantes para a identificação do objeto da experiência, refletindo, não o real, mas um ponto de vista sobre o real, como salienta Samira Chalhub. ${ }^{3}$ Afinal de contas, um conceito demarcado é sempre seletor de propriedades, já que os infinitos aspectos do real passam pelo juízo de valor expedido pelo autor do ato de fala, no caso, o legislador.

A esta altura, já podemos dizer que o enunciado factual é protocolar, surpreendendo uma alteração devidamente individualizada do mundo fenomênico, com a clara determinação das condições de espaço e de tempo em que se deu a ocorrência. Articulação de linguagem organizada assim, com esse teor de denotatividade, chamaremos de fato, fato político, econômico, contábil, biológico, psicológico, histórico, jurídico etc. No Direito Positivo, correspondem ao antecedente das normas individuais e concretas. É aqui que se encontra a grande divergência interpretativa atual. Será que este fato que dá causa a uma relação jurídica poderá ser objeto de outras qualificações que não a jurídica?

3 CHALHUB, Samira. Funções da linguagem. São Paulo: Ática. 1991. 
Em outras palavras, o fato antecedente da norma no Direito Positivo poderá ser entendido como fato econômico, fato contábil, fato político ou mesmo fato histórico? É o que iremos discutir.

Antes, porém, faço voltar a atenção à premissa de que o status dos fatos é diferente do status dos objetos a que se referem. O evento, na visão ontológica, no sentido de realidade social concreta, para vestir o caráter jurídico precisa ser transcrito em linguagem competente, ou seja, aquela linguagem juridicamente admitida como capaz para constituir o antecedente normativo e estabelecer o vínculo relacional entre agentes do Direito no plano concreto e individual. Outrossim, não é qualquer função pragmática da linguagem que propicia a composição de um enunciado factual. Além da linguagem descritiva, indicativa ou declarativa, muito usada na comunicação diária e no discurso científico, torna-se possível emitir enunciados fácticos também em linguagem prescritiva e em linguagem operativa ou performativa. Obviamente que os valores lógicos de tais enunciados serão os inerentes ao uso empregado: verdadeiro e falso, para o descritivo; válido e não-válido para o prescritivo; e eficaz e ineficaz para o performativo. A despeito da função, contudo, em todos eles haverá, necessariamente, um quantum de referencialidade, uma vez que são formações lingüísticas vertidas para o mundo fenomênico das coisas, projetando-se no domínio dos objetos da experiência. Na composição de tais enunciados sobre as regras que orientam a boa formação sintática, hão de observar-se os usos do idioma, sem o que o sentido daquelas estruturas não será apto para fins denotativos. E esses fins reclamam a identificação da ocorrência num intervalo de tempo e num ponto do espaço, dentro da conotatividade de uma hipótese autorizadora da construção do fato jurídico. Serão, portanto, necessariamente, determinativos. Por isso, o verbo há de estar no presente ou no passado, excluindo-se o futuro.

\section{Disciplinariedade e autonomia do Direito}

A escolha do caráter disciplinar ou interdisciplinar, como estratégia para a construção do discurso científico, além de opção incontornável, continua sendo tema discutido nos círculos epistemológicos, juntamente com a própria amplitude da interrelação das disciplinas, conteúdo de outra decisão a ser tomada pelo cientista. Tudo para perseguir aquele quantum de objetividade que pretende ter contraparte na carga mínima de subjetividade no agente do conhecimento.

Têm-se como certo, nos dias de hoje, que o conhecimento científico do fenômeno social, seja ele qual for, advém da experiência, aparecendo sempre como uma 
síntese necessariamente a posteriori. Ele, o fato social, na sua congênita e inesgotável plurilateralidade de aspectos, reivindica, enquanto objeto, uma seqüência de incisões que lhe modelem o formato para a adequada apreensão do espírito humano. Está presente nessa atividade tanto a objetivação do sujeito como a subjetivação do objeto, em pleno relacionamento dialético.

Sem disciplinas, é claro, não teremos as interdisciplinas, mas o próprio saber disciplinar, em função do princípio da intertextualidade, avança na direção de outros setores do conhecimento, buscando a indispensável complementariedade. O paradoxo é inevitável: o disciplinar leva ao interdisciplinar e este último faz retornar ao primeiro. A relação de implicação e polaridade, tão presente no pensamento de Miguel Reale, manifesta-se também aqui, uma vez que o perfil metódico que venha a ser adotado, sê-loá, certamente, para demarcar uma porção da cultura.

Dois outros obstáculos, na forma de desafios, estarão no caminho do estudioso, mesmo que se admita superada aquela situação paradoxal: (i) quais as proporções do corte e (ii) que critérios utilizar para a condução do raciocínio no trato com o objeto já constituído (digamos, recortado)?

Aquilo que podemos esperar de quem empreenda a aventura do conhecimento, no campo do social, a esta altura, é uma atitude de reflexão, de prudência, em respeito mesmo às intrínsecas limitações e à própria finitude do ser humano. Esta tomada de consciência, contudo, não pode representar a renúncia do seguir adiante, expressa nas decisões que lhe parecerem mais sustentáveis ao seu projeto descritivo.

5. Interpretação dos fatos: delimitação do conteúdo de "fato puro", "fato contábil" e "fato jurídico"

Retornemos da digressão para considerar que, no degrau da hermenêutica jurídica, o grande desafio de quem pretende desvelar o conteúdo, sentido e alcance das regras de direito radica na inafastável dicotomia entre a letra da lei e a natureza do fenômeno jurídico subjacente.

O desprestígio da chamada interpretação literal é algo que dispensa meditações mais profundas, bastando recordar que, prevalecendo como método de interpretação do Direito, seríamos forçados a admitir que os meramente alfabetizados, quem sabe com o auxílio de um dicionário de tecnologia jurídica, estariam credenciados a identificar a substância das mensagens legisladas, explicitando as proporções de significado da lei. $\mathrm{O}$ reconhecimento de tal possibilidade roubaria à Hermenêutica Jurídica e à Ciência 
do Direito todo o teor de suas conquistas, relegando o ensino universitário a um esforço sem expressão e sentido prático de existência. Talvez por isso, e sem o perceber, Carlos Maximiliano haja sufragado, com suficiente ênfase, que todos os métodos interpretativos são válidos, desde que seus resultados coincidam com aqueles colhidos na interpretação sistemática.

Não sobeja repetir: para nós, as normas jurídicas são as significações que a leitura do texto desperta em nosso espírito e, nem sempre, coincidem com os artigos em que o legislador distribui a matéria no campo escrito da lei. Dito de outro modo, na realidade social em que vivemos, experimentamos sensações visuais, auditivas, tácteis, que suscitam noções. Estas, agrupadas em nosso intelecto, fazem surgir os juízos ou pensamentos que, por sua vez, se exprimem, verbalmente, como proposições. A proposição aparece como o enunciado de um juízo, da mesma maneira que o termo expressa uma idéia ou noção. E a norma jurídica é, exatamente, o juízo hipotético que a percepção do texto provoca no plano de nosso consciente, da mesma forma em que tantas outras noções não-jurídicas poderiam ter sido originadas daquele mesmo conjunto de percepções físicas. Diz-se, portanto, que a noção é jurídica, pois se enquadrou a uma determinada hipótese jurídica.

Por analogia aos símbolos lingüísticos quaisquer, é válida a construção segundo a qual o texto escrito está para a norma jurídica, tal qual o vocábulo está para sua significação. E adotando-se a estrutura trilateral, de inspiração husserliana, falaremos em suporte físico, significado e significação. Transportadas as idéias para o domínio do jurídico: o suporte físico é o conjunto dos textos do direito posto; significado, a conduta humana compartida, na vida social; e significação, o vasto repertório que o jurista extrai, compondo juízos lógicos, a partir do contato sensorial com o suporte físico, e com referência ao quadro dos fatos e das condutas juridicamente relevantes. É exatamente na significação e no significado que se dá a construção hermenêutica do fato jurídico e onde centralizaremos todas as nossas atenções, a fim de compor estudo semântico sobre a expressão "fato jurídico".

Quer isto exprimir, por outros torneios, que a única forma de se entender o fenômeno jurídico, conclusivamente, é analisando-o como um sistema, visualizado no entrelaçamento vertical e horizontal dos inumeráveis preceitos que se congregam e se aglutinam para disciplinar o comportamento do ser humano, no convívio com seus semelhantes. O texto escrito, na singela expressão de seus símbolos, não pode ser mais do que a porta de entrada para o processo de apreensão da vontade da lei, jamais confundida com a intenção do legislador. Sem nos darmos conta, adentramos à análise do sistema normativo sob o enfoque semioticista, recortando, como sugere uma análise mais séria, 
a realidade jurídica em seus diferentes campos cognoscitivos: sintático, semântico e pragmático.

Bem sabido que não se pode priorizar qualquer das dimensões semióticas, em detrimento das demais. Todavia, o momento semântico num exame mais apurado sobre o tema que ora tratamos, chama a atenção pela maneira intensa como qualifica e determina as questões submetidas ao processo dialógico que prepara a decisão ou conclusão. Daí exclamar Alfredo Augusto Becker, cheio de força retórica, que o jurista nada mais seria que o semântico da linguagem do Direito. A ele cabe a árdua tarefa de examinar os textos, quantas vezes obscuros, contraditórios, penetrados de erros e imperfeições terminológicas, para captar a essência dos institutos, surpreendendo, com nitidez, a função da regra, no implexo quadro normativo.

No processo de cognição da linguagem prescritiva de condutas, o hermeneuta esbarra em numerosos entraves que a realidade jurídica mesma lhe impõe. O primeiro obstáculo está cravado na própria matriz do Direito. A produção das normas de mais elevada hierarquia no sistema, que são gerais e abstratas, está confiada aos parlamentos, casas legislativas de natural heterogeneidade, na medida em que se pretendam democráticas e representativas. Com isso, a despeito dos esforços na elaboração de uma linguagem técnica, dotada da racionalidade suficiente para atingir padrões satisfatórios de eficácia social, a verdade é que a mensagem legislada quase sempre vem penetrada de imperfeições, com problemas de ordem sintática e semântica, tornando, muitas vezes, difícil sua compreensão pelos sujeitos destinatários. É neste ponto que a Dogmática (Ciência do Direito em sentido estrito) cumpre papel de extrema relevância, compondo os enunciados freqüentemente dispersos em vários corpos legislativos, ajeitando-os na estrutura lógica compatível e apontando as correções semânticas que a leitura contextual venha a sugerir. Com tais ponderações, a comunicação normativa flui mais facilmente do emissor ao receptor, realizando os propósitos da regulação jurídica com mais clareza e determinação.

Num segundo momento, depara-se o estudioso com uma realidade juridicamente complexa.Analisando, no contexto de uma visão sistemática, onde as unidades normativas se entreligam formando uma estrutura sintática; onde há, inequivocamente, um referente semântico consubstanciado pela região material das condutas, ponto de confluência das iniciativas reguladoras do comportamento intersubjetivo; e onde se verificam as inesgotáveis manifestações dos fatores pragmáticos. Tudo isso, repito, traz ao estudo do fenômeno jurídico complexidades imensas. Na qualidade de exegeta, deve partir da literalidade do texto, e buscar as significações sistêmicas, aquelas que retratam os 
específicos parâmetros instituídos pelo sistema. Do mesmo modo, a consistência material das regras há de encontrar fundamento no sistema, sob pena de não prevalecerem, vindo a ser desconstituídas. Daí a tendência para cortar cerce o problema, ofertando soluções simplistas e descomprometidas, como ocorre, por exemplo, com a canhestra "interpretação literal" das formulações normativas, que leva consigo a doce ilusão de que as regras do Direito podem ser isoladas do sistema e, analisadas na sua compostura frásica, desde logo "compreendidas".

Adotando tal postura, parece-nos perfeitamente justificada e coerente a adoção da afirmativa adotada de que as regras jurídicas são as significações que a leitura do texto desperta em nosso espírito e, nem sempre, coincidem com os dispositivos mediante os quais o legislador distribui a matéria no corpo escrito da lei. Advém daí que, muitas vezes, um único artigo não seja bastante para a compreensão da norma, em sua integridade existencial. Vê-se o leitor, então, na contingência de consultar outros preceitos do mesmo diploma e, até, a sair dele, fazendo incursões pelo sistema.

Por fim, não nos esqueçamos de que a camada lingüística do Direito está imersa na complexidade do tecido social, cortada apenas para efeito de aproximação cognoscitiva. O real, com a multiplicidade de suas determinações, só é suscetível de uma representação intuitiva, porém aberta para receber inúmeros recortes cognoscitivos. Com tais ponderações, torna-se hialina a afirmativa de que de um mesmo evento, poderá o jurista construir o fato jurídico, como também o contabilista, o fato contábil e o economista, o fato econômico. Tudo, portanto, sob a dependência do corte que se quer promover daquele evento.

E quanto ao âmbito de compreensão deste fenômeno, retornando à linha de raciocínio inicial, citemos que todos os fatos são construções de linguagem, e, como tanto, são representações metafóricas do próprio evento. Seguem a gramaticalidade própria do universo lingüístico a que pertencem - o jurídico - quando constituinte do fato jurídico ou o contábil, por exemplo, quando construtores do fato contábil. As regras da gramática cumprem função lingüística reguladora de um idioma historicamente dado. Prescrevem a forma de combinação dos vocábulos e das expressões para produzirmos oração, isto é, construção com sentido daquele universo lingüisticamente dado. O Direito, portanto, é linguagem própria compositiva de uma realidade jurídica. Provém daí o nominar-se Gramática Jurídica ao subconjunto das regras que estabelecem como outras regras devem ser postas, modificadas ou extintas, dentro de certo sistema.

Posto isso, perceberemos que a construção do fato jurídico, nada mais é que a constituição de um fraseado normativo capaz de justapor-se como antecedente normativo 
de uma norma individual e concreta, dentro das regras sintáticas ditadas pela gramática do Direito, assim como de acordo com os limites semânticos arquitetados pela hipótese da norma geral e abstrata.

Há que ter em mente, nesse caminho, uma importante informação: as palavras componentes desta frase constitutiva de realidade jurídica têm uma denotação, que é o conjunto dos significados que, posteriormente, representam o signo. Ao mesmo tempo, as mesmas palavras classificam-se dicotomicamente, na medida em que estabelecem duas categorias: a dos objetos que representam e a dos objetos que não-representam.

Tal ocorre com a expressão fato jurídico. Têm-se como certo, nos dias de hoje, que o conhecimento científico do fenômeno social, seja ele qual for, advém da experiência, aparecendo sempre como uma síntese necessariamente a posteriori. $\mathrm{Na}$ constituição do fato jurídico, a análise relacional entre a linguagem social e a linguagem jurídica, redutora da primeira, sobrepõe-se a esse conhecimento sinzetético, obtendo como resultado um novo signo, individualizado no tempo e no espaço do Direito e recebendo qualificação jurídica: eis o fato jurídico. É, portanto, uma construção de sobrelinguagem. Há duas sínteses: (i) do fenômeno social ao fenômeno abstrato jurídico e (ii) do fenômeno abstrato jurídico ao fenômeno concreto jurídico.

Adotados estes pressupostos, verificaremos que o termo ou expressão que adquirir o qualificativo "jurídico" não-somente será representativo de uma unidade do universo do Direito, como também denotará seu contraponto, que são todos os outros fatos lingüisticamente possíveis de serem construídos, a partir daquele mesmo evento, mas que não se enquadram às regras sintáticas e semanticamente dadas pelo sistema de linguagem do Direito. A demarcação do objeto implica a delimitação do corte de sua classe e, ao traçar esses limites o exegeta obtém como resultado indireto a formação do conjunto dos fatos que não se qualificam como tal. Trata-se de singela construção resultante da lógica, pois, no universo das proposições normativas, " $p$ ” (proposição) é diferente e oposto de " $n$ $p$ " (não-proposição), impedindo a quem se dispõe a conhecer o sistema incluir a classe " $n$ $p$ " dentro do conjunto " $p$ ". São categorias que tomam o mesmo universo mas que não se intercruzam. Ou seja, de um mesmo evento pode-se construir um fato jurídico ou um fato contábil; mas um e outro são sobremaneira diferentes, o que impede de inscrever o último como antecedente da norma individual e concreta, dado que representa unidade carente de significação jurídica. O fato capaz de implicar o conseqüente normativo haverá de ser sempre fato jurídico, mesmo que muitas vezes haja situações em que num e noutro estejam presentes os mesmos conteúdos denotativos. A partir desses dados, é que poderemos demarcar o conjunto dos fatos jurídicos, separando-o do conjunto dos fatos não-jurídicos, 
onde se demoram os fatos econômicos, os fatos contábeis, os fatos históricos e tantos outros quantas sejam as ciências que os constroem. $\mathrm{O}$ critério utilizado para a separação desses dois domínios é justamente a homogeneidade sintática do universo jurídico.

Com tais considerações, cabe relembrar que todo conhecimento do objeto requer cortes e mais recortes científicos, que cumprem a função de simplificar a complexa realidade existencial delimitando o campo da análise. Não nos esqueçamos de que a camada lingüística do Direito está imersa na complexidade do tecido social, cortada apenas para efeito de aproximação cognoscitiva. O Direito Positivo é objeto do mundo da cultura e, como tal, torna árdua a tarefa do exegeta em construir a plenitude de seus conteúdos de significação, obrigando-o a reduzir a complexidade empírica, ora isolando ora selecionando caracteres do dinâmico mundo do existencial. Ele, o fato social, na sua congênita e inesgotável plurilateralidade de aspectos, reivindica, enquanto objeto, uma seqüência de incisões que lhe modelem o formato para a adequada apreensão pelo espírito humano. Está presente nessa atividade tanto a objetivação do sujeito como a subjetivação do objeto, em pleno relacionamento dialético. O objeto passa a ser uma construção em linguagem do intérprete que reduz as características próprias e imanentes daquilo que se toma do universo físico-social.

Eis uma barreira intransponível à concepção do "fato puro", seja ele econômico, histórico, político, jurídico ou de qualquer outra qualidade que se lhe pretenda atribuir. Tais fatos, como acrescenta Lourival Vilanova, são elaborações conceptuais, subprodutos de técnicas de depuração de idéias seletivamente ordenadas. ${ }^{4}$ Cravo a premissa segundo a qual não é possível, por isso mesmo, isolar-se, dentro do social, o fato jurídico, sem uma série de cortes que representem, numa ascese temporária, o despojamento daquele fato cultural maior de suas colorações políticas, econômicas, éticas, históricas etc., bem como dos resquícios de envolvimento do observador, no incessante fluxo de sua estrutura emocional.

Cumpre fazer observação importante e que atina ao momento da própria consolidação da afirmativa acima exposta. Isto porque a doutrina tradicional vem conotando certos fatos jurídicos, tal qual o fato elisivo, como construção de conteúdo econômico, com efeitos jurídicos. Assim o entende, Amílcar de Araújo Falcão, que o qualifica como fato jurídico de conteúdo econômico ou mesmo fato econômico de relevância jurídica. Distrações desse gênero, conduziram o pensamento à idéia de que seja necessário ao Direito tomar emprestado o fato econômico para cumprir com suas funções prescritivas de

4 Confira: "O fato puro não leva, com ele, a suficiente relevância significativa para ser incluído dentro do tipo. Para ingressar, sofre uma valoração comandada por um dever-ser.” (VILANOVA, Lourival. op. cit., p. 104.) 
conduta. O fato elisivo, em si, abstinha-se da natureza jurídica. Bem, passemos a examinar os critérios que compõem as mencionadas proposições afirmativas.

No desejo de construir um recorte da realidade que cerque o fato jurídico elisivo, pensamentos deslizam ao longo do eixo descritivo, impulsionados por uma eloqüência ordenada e vigorosa, bem na medida que a Ciência recomenda. Afinal de contas, que fato é esse? Como qualificá-lo? Sob qual critério? Nunca é demais insistir que as subdivisões em sistemas respondem a cortes metódicos que os objetivos da investigação analítica impõem ao espírito do pesquisador. O critério adotado no corte é o que qualificará o fato construído por ele, quantificando-o, inclusive, em seu conseqüente normativo. Se adotarmos um critério jurídico, o fato será atribuído ora como jurídico ora como nãojurídico, de acordo com as características instituídas em lei que determinam os contornos daquele factum tributário. Adotando tal pressuposto, a referência estará sempre contida nos critérios legalmente estipulados.

Ao indagarmos sobre a expressão economia fiscal, em olhar ligeiro, entenderemos estar nos limites entre o que é do domínio econômico e o que é do Direito. Em qual desses domínios o critério se insere? Cumpre observar que, ao estabelecermos o paralelo entre o resultado de duas situações fiscais, estamos ingressando em uma análise aritmética entre duas quantias ou dois resultados numéricos. Seria esta uma análise jurídica ou econômica? Vejamos. Transportando-se isto para o quadro das prescrições legais tributárias, iremos verificar no próprio art. $3^{\circ}$ do CTN que tributo é um prestação pecuniária compulsória, em moeda ou cujo valor nela se possa exprimir. Em outras palavras, tributo é um valor pecuniário. O próprio art. $4^{\circ}$ do $\mathrm{CTN}$, ao dizer que a natureza específica do tributo é definida pelo fato gerador, está confirmando que a natureza da exigência é dada pela conjugação da hipótese da incidência e da base de cálculo, assumindo, nesta operação, perfil numérico.

Pelo exposto, fica a ressalva de que não há fatos jurídicos puros ou fatos econômicos puros. Aquilo que existe são cortes de linguagem. Nós, juristas, montamos a realidade que representa o corte. Desta maneira, construímos a interpretação jurídica. Nada disso impede que economistas tomem a mesma base objetiva e gerem enunciados econômicos sobre ela. Produzem-se, por suavez, outros cortes sobre o mesmo acontecimento, compondo novo signo. E a mesma coisa ocorre para o historiador, que constitui o fato histórico; para o sociólogo, que constrói o fato sociológico, entre tantos outros recortes que se possam compor naquela realidade. À confusão metodológica que se estabelece no instante do corte Becker chamou de "mancebia irregular" do Direito Tributário com outras ciências. Aliás, foi precisamente pela pretensão de fixar como objeto a atividade 
financeira do Estado, passando a examiná-la sob todos os ângulos possíveis e imaginários, sem qualquer prioridade metodológica, que a Ciência das Finanças rotundamente faliu, não mais existindo como disciplina nas grades curriculares das Faculdades de Direito do Brasil.

Discorrendo acerca do modo de pensar algumas vezes irrefletido da doutrina tradicional, também conhecida como doutrina bem comportada do Direito Tributário, Alfredo Augusto esclarece: Exemplo de carência de atitude mental jurídica é a divulgadíssima tese (aceita como coisa óbvia) que afirma ser a hipótese de incidência("fato gerador", "fato imponível", "suporte fáctico") sempre um fato econômico. Outro exemplo atual é a muito propagada doutrina da interpretação e aplicação do Direito Tributário segundo a "realidade econômica do fenômeno social". Como se demonstrará, ambas as teorias têm como resultado a demolição da juridicidade do Direito Tributário e a gestação de um ser híbrido e teratológico: o Direito Tributário invertebrado. ${ }^{5}$ (os grifos são do autor).

\section{A concepção do direito como sistema autopoiético}

Para a teoria dos sistemas, no modelo Luhmanniano, o Direito constitui um sistema autopoiético de segundo grau, tendo adquirido autonomia em face do sistema autopoiético geral, que é a sociedade. Surgem os ordenamentos jurídicos como subsistemas autônomos pela emergência de um código próprio e diferenciado (lícito/ilícito), pronto para dar estabilidade a um processo equilibrado de auto-produção recursiva, fechada e circular de comunicações exclusivamente jurídicas. Celso Campilongo, ${ }^{6}$ em texto elucidativo, esclarece a proposição de Luhmann, mediante a qual o direito promove a generalização congruente das expectativas normativas. O jusfilósofo paulista examina, palavra por palavra, as proporções semânticas daquela mensagem, deixando bem clara a manifestação do pensador alemão.

O repertório desse sistema é formado por atos de comunicação (que pressupõem necessariamente a linguagem), articulados recursivamente, que se autoreproduzem à luz daquele código binário (lícito/ilícito), construindo seu meio-envolvente próprio (realidade jurídica) e demarcando os limites do território do Direito. Caracteriza-se este subsistema por ser normativamente fechado, porém cognitivamente aberto, vale dizer, opera por métodos que lhe são exclusivos, mas troca informações com outros subsistemas,

\footnotetext{
5 BECKER, Alfredo Augusto. Teoria geral do direito tributário. 4. ed. São Paulo: Marcial Pons/Noeses, 2006.

6 CAMPILONGO, Celso. Política, sistema jurídico e decisão judicial. São Paulo: Max Limonad, 2002. p. 19.
} 
emitindo atos comunicativos (normas) e, ao mesmo tempo, recebendo de outros subdomínios as notícias por eles produzidas. Fazendo cabedal de sua autonomia, como subsistema, o Direito processa apenas as informações que lhe interessam, submetendo-as, então, aos critérios metodológicos de formação de normas. Daí a conclusão de Marcelo Neves: ${ }^{7}$ A positivação do Direito na sociedade moderna implica o controle do códigodiferença "lícito/ilícito" exclusivamente pelo sistema jurídico, que adquire dessa maneira seu fechamento operativo.

E sobre a força e intensidade da mencionada autonomia, vale consignar a posição categórica de Gunther Teubner: ${ }^{8}$ As comunicações jurídicas constroem a "realidade jurídica" no chamado tipo ou hipótese legal de uma norma jurídica. Os elementos típicos ou facti-species normativos incorporam distinções intrinsecamente jurídicas, permitindo assim ao sistema jurídico produzir as suas próprias categorizações. Desse modo, nos actos legislativos, o direito como que inventa o seu próprio meio envolvente. E, mais adiante: Quer dizer: de um ponto de vista construtivista, as intervenções do direito na economia devem ser entendidas como observações reciprocas entre dois sistemas de comunicação hermeticamente fechados e autônomos. O direito "inventa" uma imagem da economia, formulando as respectivas normas com referência a tal imagem. A economia "inventa" uma imagem do direito, processando os actos de pagamento também com referência a esta. E embora estes modelos imaginários intra-sistêmicos do mundo exterior possam ser continuamente refinados, como acontece com a moderna escola da análise econômica do direito, a verdade é que isto jamais nos conduzirá das concepções jurídicas do sistema econômico à realidade do próprio sistema econômico". 9

Vê-se como fica reforçada a tese da autonomia do Direito, quando tratada pela Teoria dos Sistemas.

7. A impossibilidade de traduções perfeitas entre os idiomas da mesma família e a conversação que entre eles se estabelece, segundo a concepção de Vilém Flusser

No seu Língua e Realidade, Flusser dá uma contribuição valiosa ao estudo da tradução entre idiomas. Além de estabelecer proposições sugestivas a respeito de a língua ser a realidade, formar a realidade e criar a realidade, mencionando a conversação que se institui entre tais ordens para formar as várias culturas, o pensador Tcheco proclama, com

7 NEVES, Marcelo. A constitucionalização simbólica. São Paulo: Editora Acadêmica, 1994. p. 119-120.

8 TEUBNER, Gunther. O Direito como sistema autopoiético. Lisboa: Fundação Calouste Gulbenkian, 1993. p. 157.

9 Id. Ibid., p. 160. 
bastante clareza, que as ciências são línguas, de tal modo que as observações aplicáveis aos sistemas idiomáticos se acomodam perfeitamente ao esquema organizacional das ciências. Ouçamô-lo. A ciência sensu stricto, tal qual a conhecemos no Ocidente, desde o Renascimento, equivale, deste ponto de vista, ao aparecimento de uma nova língua. ${ }^{10}$ E Gustavo Bernardo Krause, ao prefaciar essa obra prima, como ele mesmo reconhece, reproduz o texto de Flusser: a ciência, longe de ser válida para todas as línguas, é ela própria uma língua a ser traduzida para as demais. ${ }^{11}$

Vilém Flusser, de fato, não admite a possibilidade de tradução perfeita, mesmo em se tratando de línguas flexionais, com organizações parecidas. Torna-se possível aproximadamente, graças às semelhanças existentes entre as estruturas dos idiomas. Daí o adágio consagrado: tradutore, traditore. Entre as realidades criadas e formadas por duas línguas diferentes, ainda que semelhantes, há um abismo que tem de ser transposto, momento em que surgem as inevitáveis distorções.

Ora, se o Direito (tomado aqui como Ciência) e a Economia, são dois sistemas cognoscentes distintos, entre eles somente poderá haver uma tradução aproximada, com a presença de termos e expressões intraduzíveis que determinam freqüentes descompassos. Podem, contudo, manter uma conversação ampla, que envolva também o saber a respeito de outros segmentos do tecido social, como a Ciência Política, a Sociologia (em sentido estrito), as Ciências Contábeis, a Psicologia Social, a História etc.

\section{Conclusão}

Com apoio nos argumentos que acabo de expor, na forma de premissas, torna-se intuitiva a conclusão segundo a qual os fatos, assim como toda construção de linguagem, podem ser observados como jurídicos, econômicos, antropológicos, históricos, políticos, contábeis etc.; tudo dependendo do critério adotado pelo corte metodológico empreendido. Existe interpretação econômica do fato? Sim, para os economistas. Existirá interpretação contábil do fato? Certamente, para o contabilista. No entanto, uma vez assumido o caráter jurídico, o fato será, única e exclusivamente, fato jurídico; e claro, fato de natureza jurídica, não-econômica ou contábil, entre outras matérias. Como já anotado, o Direito não pede emprestado conceitos de fatos para outras disciplinas. Ele mesmo constrói sua realidade, seu objeto, suas categorias e unidades de significação.

\footnotetext{
${ }^{10}$ FLUSSER, Vilém. Língua e realidade. 2. ed. São Paulo: Editora Anna Blume, 2004. p. 54.

${ }^{11}$ Id. Ibid., p. 19.
} 
O paradoxo inevitável, e que causa perplexidade no trabalho hermenêutico, justifica a circunstância do disciplinar levar ao interdisciplinar e este último fazer retornar ao primeiro. Sem disciplinas, portanto, não teremos as interdisciplinas; mas o próprio saber disciplinar, em função do princípio da intertextualidade, avança na direção dos outros setores do conhecimento, buscando a indispensável complementariedade. Tanto o jurídico quanto o econômico fazem parte do domínio social e, por ter este referente comum, justifica-se que entre um e outro haja aspectos ou áreas que se entrecruzem, podendo ensejar uma tradução aproximada e, em parâmetros mais amplos, uma densa e profícua conversação.

São Paulo, junho de 2007.

Referências

BECKER, Alfredo Augusto. Teoria Geral do Direito Tributário. 4. ed. São Paulo: Marcial Pons/ Noeses, 2007.

CHALHUB, Samira. Função da linguagem. 5. ed. São Paulo: Ática, 1991.

FLUSSER, Vilém. Lingua e realidade. 2. ed. São Paulo: Editora Anna Blume, 2004.

TEUBNER, Gunther. O Direito como sistema autopoiético. Tradução e prefácio de José Engrácia Antunes. Lisboa: Fundação Calouste Gulbenkian, 1993.

VILANOVA, Lourival. Estruturas lógicas e o sistema de Direito Positivo. São Paulo: Noeses, 2006.

. As estruturas lógicas e o sistema do Direito Positivo. São Paulo: Revista dos Tribunais, 1977. 